\title{
PENGARUH UNJUK KERJA (STROKE UP) TERHADAP PERFORMA MESIN PADA MOTOR 4 LANGKAH YANG MENGGUNAKAN VARIASI (CRANKSHAFT CG200)
}

\author{
EFFECT OF PERFORMANCE(STROKEUP)ON PERFORMANCE MACHINE 4 STEP \\ MOTOR USING THE VARIATIONS (CG2OO CRANKSHAFT)
}

\author{
Ariyanto $^{1}$, Nely Ana Mufarida, S.T., M.T. ${ }^{2}$, Kosjoko, S.T., M.T. ${ }^{3}$ \\ ${ }^{1}$ Mahasiswa, ${ }^{2}$ Dosen Pembimbing 1, ${ }^{3}$ Dosen Pembimbing 2, Program Studi Teknik Mesin, Fakultas \\ Teknik, Universitas Muhammadiyah Jember \\ Email: ariy7532@gmail.com
}

\begin{abstract}
ABSTRAK
Tujuan penelitian ini adalah untuk mengetahui adanya perbedaan daya, torsi dan konsumsi bahan bakar yang dihasilkan sepeda motor yang divariasi dengan poros engkol (Crankshaft) standar dan poros engkol (Crankshaft) CG200 yang menggunakan bahan bakar pertamax. Metode penelitian yang digunakan adalah eksperimen, dilakukan pada sepeda motor 4 langkah $160 \mathrm{CC}$. Data hasil penelitian dianalisa dengan cara mengamati secara langsung hasil eksperimen kemudian menyimpulkan dan menentukan hasil penelitian yang telah dilakukan dalam bentuk grafik dan tabel. Pada pengujian ini digunakan alat dynamometer untuk mengetahui daya dan torsi yang dihasilkan, sedangkan untuk pengujian laju konsumsi bahan bakar menggunakan alat buret ukur, kemudian dilakukan perhitungan konsumsi bahan bakar. Perbedaan daya sekitar 49,7 \%, dihasilkan oleh poros engkol (Crankshaft) standard yang di ambil rata-rata sekitar 9,7 HP dan pada poros engkol (Crankshaft) CG200 yaitu 19,3 HP. Perbedaan torsi sekitar 46,5\%, dihasilkan oleh poros engkol (Crankshaft) standard yang di ambil rata-rata sekitar 10,5 Nm dan pada poros engkol (Crankshaft) CG200 yaitu 19,65Nm. konsumsi bahan bakar terendah diperoleh pada motor yang menggunakan poros engkol (crankshaft) CG200 yaitu sebesar 1,2 liter/jam, sedangkan konsumsi bahan bakar terbesar didapat pada penggunaan poros engkol (crankshaft) standar yaitu sebesar 1,5 liter/jam. Perbedaan daya dan torsi yang dihasilkan lebih maksimal karena perbedaan panjang langkah dari poros engkol yang membuat rasio kompresi semakin tinggi.

Kata Kunci : Motor 4 langkah, Variasi Crankshaft, Motor Bakar.
\end{abstract}

\section{ABSTRACT}

The research objective was to determine the difference in power, torque and fuel consumption produced motorcycle varied by the crankshaft (crankshaft) standards and the crankshaft (crankshaft) that uses fuel CG200 pertamax. The method used is an experiment, carried out on a motorcycle 4 stroke 160 CC. Data were analyzed by means of directly observing the experiment results then summed and determine the results of research that has been done in the form of graphs and tables. In this test dynamometer used tool to determine the power and torque generated, while testing for fuel consumption rate using a measuring buret, then calculate the fuel consumption. Power difference of about 49.7\%, generated by the crankshaft (crankshaft) standard which is taking the average - average about 9.7 HP and the crankshaft (crankshaft) CG200 is 19.3 HP. Torque difference of about 46.5\%, generated by the crankshaft (crankshaft) standard which is taking the average - average about 10.5 $\mathrm{Nm}$ and the crankshaft (crankshaft) CG200 is 19,65Nm. The lowest fuel consumption obtained at the motor that uses the crankshaft (crankshaft) CG200 is equal to 1.2 liters / hour, while the largest fuel consumption obtained at the use of the crankshaft (crankshaft) that the standard of 1.5 liters / hour. Differences in power and maximum torque generated due to the difference in length of the crankshaft steps that make the higher compression ratio. 
Keyword: Motor 4 steps, Variation Crankshaft, Motor Fuel

\section{PENDAHULUAN}

Perkembangan teknologi pada saat ini yang semakin pesat, mendorong meanusia untuk selalu menciptakan inovasi. Inovasi teknologi didalam bidang otomotif semakin pesat, khususya pada motor bakar. Motor bakar merupakan salah satu mesin pembakaran dalam atau sering disebut dengan istilah internal combustion engine yaitu mesin yang mengubah energy panas menjadi mekanik, energy itu sendiri dapat diperoleh dari peruses pembakaran. Salah satu alat trasnprotasi kendaraan bermesin yang yang sederhana yang banyak digunakan pada saat ini adalah sepeda motor. Perbandingan kompresi merupakan suatu perbandingan antara besarnya volume total silinder dengan volume ruang bakar.volume total siinder adalah penjumlaha dari volume ruang bakar dan volume langkah. Volume ruang bakar adalah volume diatas torak pada titik mati atas (TMA). Volume langkah adalah volume di atas torak sewaktu torak ada pada titik mati bawah (TMB) sampai garis titik mati atas (TMA). Volume langkah merupakan hasil dari perkalian dari luas permukaan torak dan panjang langkah torak. Semakin besar diameter torak dan panjang langkah dari suatu mesin sepeda motor maka akan semakin besar volume langkahnya.

Hal ini akan mempengaruhi nilai perbandingan kompresi menjadi semakin tinggi. Tingginya perbandingan kompresi menetukan besarnya tekanan pembakaran campuran bahan bakar dan udara didalam silinder. Crankshaft CG200 dipilih karena sangat cocok diaplikasikan pada mesin 4 langkah 160 CC yang memiliki kesamaan karakteristik pada bagian mesin dan mempermudah pemasangan tanpa harus merubah komponen-komponen mesin lainya. Crangkshaft atau (poros engkol) CG200 yang memiliki panjang langkah $62.2 \mathrm{~mm}$ lebih tinggi dari poros engkol standar milik mesin $160 \mathrm{CC}$ yang hanya memiliki panjang langkah $49.5 \mathrm{~mm}$ perbedaan dua tipe poros engkol ini sangat berpengaruh terhadap performa mesin, langkah stroke up yang lebih panjang akan memperoleh kompresi yang lebih maksimal.

Adapun cara lain dengan memperpanjang langkah piston dengan cara memindah kedudukan pin poros engkol (big end) menjadi lebih tinggi (stroke up). Stroke up artinya menaikan panjang langkah piston.
Stroke up dilakukan dengan mengubah posisi poros piston diporos engkol (big end) menjadi lebih jauh atau menggeser big end standart menjadi lebih dekat ke tepi daun poros engkol, tapi cara ini sangat berpengaruh pada tingkat kekuatan pada dinding poros engkol jika terjadi panas yang berlebih maka memungkintan terjadinya kerusakan atau keretakan pada tepi daun poros engkol.

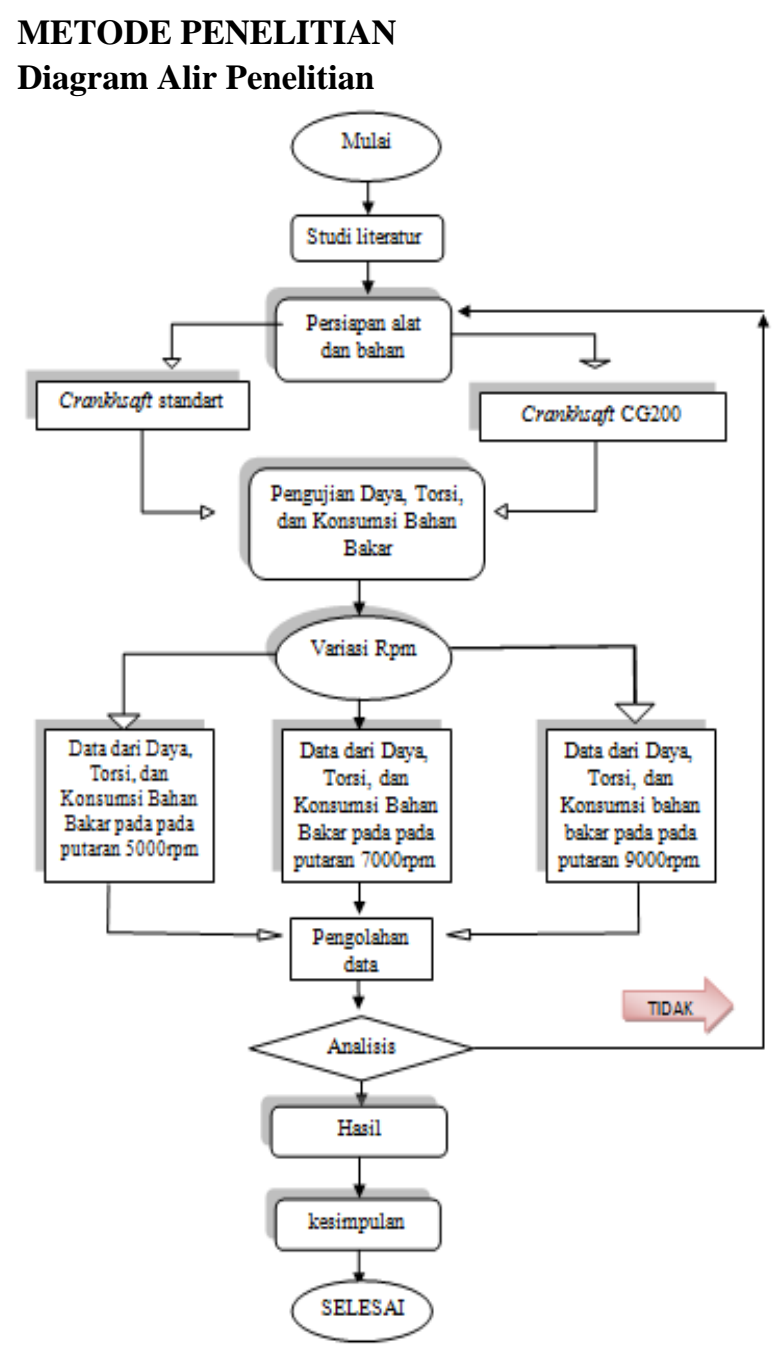

Gambar 1. Diagram Alir Penelitian

\section{Alat dan Bahan}

Alat yang digunakan untuk mengukur daya dan torsi adalah dynamometer, dengan beberapa peralatan pendukung seperti: stopwatch, buret ukur dan tool set. Skema penelitian ditunjukan pada gambar 2 . 


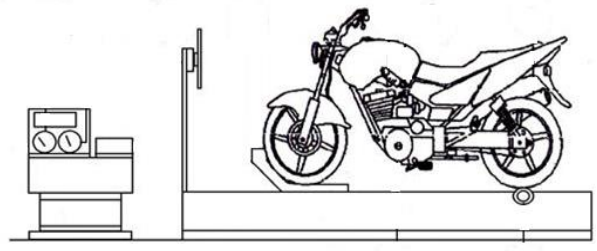

Gambar 2. Skema Alat Uji Dynotes (Dahayu, 2016:07)

Dynamometer terdiri dari suatu rotor yang digerakkan oleh motor yang akan diukur dan berputar dalam medan magnet. Kekuatan medan magnetnya dikontrol dengan mengubah arus sepanjang susunan kumparanyang ditempatkan pada kedua sisi rotor. Rotor ini berfungsi sebagai konduktor yang memotong medan magnet. Karena pemotongan medan magnet tersebut maka terjadi arus dan arus diinduksikan dalam rotor sehingga rotor menjadi panas.

Bahan penelititan yang digunakan ialah motor 4 langkah 160 CC. Untuk spesifikasinya sebagai berikut:

- Panjang X lebar X tinggi : 2.034 x 754 x 1.065 $\mathrm{mm}$

- Berat kosong : $126 \mathrm{~kg}$ (tipe spoke) / $127 \mathrm{~kg}$ (tipe $\mathrm{CW}$ )

- Tipe suspensi belakang : Belakang swing arm, double shockbreker

- Ukuran ban depan : 2,75 - 18 - 42P

- Ukuran ban belakang : 3,00 - 18 - 47P

- Rem belakang : Tromol

- Kapasitas tangki bahan bakar : 13,2 liter

- Tipe mesin : 4 langkah, SOHC, pendinginan udara

- Diameter x langkah : 63,5 x 49,5 mm

- Volume langkah : 156,7 cc

- Perbandingan kompresi : 9,0:1

- Daya maksimum :13,3 PS / 8.500 RPM

- Torsi maksimum : 1,3 kgf.m / 6.000 Rpm

- Gigi transmsi : 5 kecepatan, bertautan tetap

- Aki : 12 V - 5 Ah.

\section{Prosedur Pengujian}

1. Sebelum melakukan pengujian kita perlu mempersiapkan alat dan bahanyang akan digunakan dalam pengujian. Alat yang akan digunakan yaitu tool set, buret ukur, stopwatch dan dynamometer. Bahan yang digunakan yaitu dua jenis poros engkol (standar dan modifikasi), dan satu unit sepeda motor 4 langkah $160 \mathrm{CC}$.

2. Setelah alat dan bahan dipersiapkan selanjutnya lakukan pengecekan kondisi sepeda motor yang akan diuji diantaranya pengecekan kondisi minyak pelumas, busi dan kabel-kabel sistem kelistrikan. Setelah pengecekan kondisi sepeda motor selesai kemudian lakukan tune up pada sepeda motor agar performa sepeda motor prima.

3. Langkah terakhir setelah melakukan tune up yaitu menaikan sepeda motor yang akan diuji pada alat dynamometer, pasang kabel tachometer pada kabel busi, lepas selang dari tangki bahan bakar pada karburator kemudian pasang selang buret pada karburator.

4. Setelah semuanya dipersiapkan maka pengujian siap dilakukan.

\section{Metode Pengujian}

Sebelum melakukan pengujian daya dan torsi, agar pengujian optimal dan valid maka bahan uji harus dalam kondisi baik. Sepeda motor terlebih dahulu harus di service secara menyeluruh dan alat sebelum digunakan dalam pengujian harus terlebih dahulu dilakukan kalibrasi dan segi keselamatan dalam pengujian harus perhatikan.

\section{Metode pengambilan data}

Langkah pengujian daya dan torsi yaitu:

1. Melakukan pengisian bahan bakar pertamax pada buret.

2. Melakukan pemanasan mesin dengan menghidupkan mesin sepeda motor sekitar 2-3 menit agar suhu kerja mesin dapat ideal.

3. Memulai membuka throttle gas sampai putaran penuh. Perubahan putaran mesin dapat dilihat pada layar monitor pada komputer yang terhubung pada dynamometer.

4. Data operasi meliputi daya, torsi, putaran mesin pada setiap putaran akan langsung terbaca pada layar monitor pada komputer.

5. Mencetak hasil pengujian berupa data daya dan torsi. Data yang dapat diperoleh berupa table dangrafik perubahan daya (HP) dan torsi $(\mathrm{Nm})$ pada setiap putaran mesin tertentu.

6. Prosedur yang sama seperti di atas dilakukan untuk masing-masing pengujian data daya dan torsi.

7. Agar di dapatkan data yang valid untuk setiap pengujian daya dan torsi dilakukan sebanyaktiga kali pada setiap jenis bahan bakar.

Langkah-langkah pengujian konsumsi bahan bakar yaitu:

1. Melakukan pengisian bahan bakar bensin pada buret. 
2. Mesin sepeda motor dihidupkan hingga putaran mesin stasioner.

3. Setelah itu mencatat berapa lama waktu yang dibutuhkan untuk konsumsi bahan bakar sebanyak $500 \mathrm{ml}$.

4. Untuk mendapatkan data konsumsi bahan bakar, data hasil penelitian dimasukkan dalam rumus, baru diketahui hasilnya.

\section{Data Penelitian}

Hasil data Daya, Torsi dan Konsumsi Bahan Bakar akan dimasukkan kedalam tabel di bawah ini:

1. Poros Engkol (Crankhsaft) Standar

a. Daya

Tabel 1. Lembar Pengambilan Data Penelitian Daya Poros Engkol (Crankshaft) Standar

\begin{tabular}{|c|c|c|c|c|c|c|}
\hline $\begin{array}{c}\text { Putaran } \\
\text { mesin }\end{array}$ & \multicolumn{5}{|c|}{ Daya (HP) } & \multirow{2}{*}{$\begin{array}{c}\text { Rata- } \\
\text { rata }\end{array}$} \\
\hline Rpm & $\begin{array}{c}\text { Pengujian } \\
\mathbf{1}\end{array}$ & $\begin{array}{c}\text { Pengujian } \\
\mathbf{2}\end{array}$ & $\begin{array}{c}\text { Pengujian } \\
\mathbf{3}\end{array}$ & $\begin{array}{c}\text { Pengujian } \\
\mathbf{4}\end{array}$ & $\begin{array}{c}\text { Pengujian } \\
\mathbf{5}\end{array}$ & \\
\hline 5000 & & & & & & \\
\hline 7000 & & & & & & \\
\hline 9000 & & & & & & \\
\hline
\end{tabular}

b. Torsi

Tabel 2. Lembar Pengambilan Data Penelitian Torsi Poros Engkol (Crankshaft) Standar

\begin{tabular}{|c|c|c|c|c|c|c|}
\hline $\begin{array}{c}\text { Putaran } \\
\text { mesin }\end{array}$ & \multicolumn{5}{|c|}{ Torsi (Nm) } & \multirow{2}{*}{$\begin{array}{c}\text { Rata- } \\
\text { rata }\end{array}$} \\
\hline Rpm & $\begin{array}{c}\text { Pengujian } \\
\mathbf{1}\end{array}$ & $\begin{array}{c}\text { Pengujian } \\
\mathbf{2}\end{array}$ & $\begin{array}{c}\text { Pengujian } \\
\mathbf{3}\end{array}$ & $\begin{array}{c}\text { Pengujian } \\
\mathbf{4}\end{array}$ & $\begin{array}{c}\text { Pengujian } \\
\mathbf{5}\end{array}$ & \\
\hline 5000 & & & & & & \\
\hline 7000 & & & & & & \\
\hline 9000 & & & & & & \\
\hline
\end{tabular}

2. Poros Engkol (Crankhaft) CG200

a. Daya

Tabel 3. Lembar Pengambilan Data Penelitian Daya Poros Engkol (Crankhaft) CG200

\begin{tabular}{|c|c|c|c|c|c|c|}
\hline $\begin{array}{c}\text { Putaran } \\
\text { mesin }\end{array}$ & \multicolumn{5}{|c|}{ Daya (HP) } & \multirow{2}{*}{$\begin{array}{c}\text { Rata- } \\
\text { rata }\end{array}$} \\
\hline Rpm & $\begin{array}{c}\text { Pengujian } \\
\mathbf{1}\end{array}$ & $\begin{array}{c}\text { Pengujian } \\
\mathbf{2}\end{array}$ & $\begin{array}{c}\text { Pengujian } \\
\mathbf{3}\end{array}$ & $\begin{array}{c}\text { Pengujian } \\
\mathbf{4}\end{array}$ & $\begin{array}{c}\text { Pengujian } \\
\mathbf{5}\end{array}$ & \\
\hline 5000 & & & & & & \\
\hline 7000 & & & & & & \\
\hline 9000 & & & & & & \\
\hline
\end{tabular}

\section{b. Torsi}

Tabel 4. Lembar Pengambilan Data Penelitian Torsi Poros Engkol (Crankhaft) CG200

\begin{tabular}{|c|c|c|c|c|c|c|}
\hline $\begin{array}{c}\text { Putaran } \\
\text { mesin }\end{array}$ & \multicolumn{5}{|c|}{ Torsi (Nm) } & \multirow{2}{*}{$\begin{array}{c}\text { Rata- } \\
\text { rata }\end{array}$} \\
\hline Rpm & $\begin{array}{c}\text { Pengujian } \\
\mathbf{1}\end{array}$ & $\begin{array}{c}\text { Pengujian } \\
\mathbf{2}\end{array}$ & $\begin{array}{c}\text { Pengujian } \\
\mathbf{3}\end{array}$ & $\begin{array}{c}\text { Pengujian } \\
\mathbf{4}\end{array}$ & $\begin{array}{c}\text { Pengujian } \\
\mathbf{5}\end{array}$ & \\
\hline 5000 & & & & & & \\
\hline 7000 & & & & & & \\
\hline 9000 & & & & & & \\
\hline
\end{tabular}

Keterangan:

Agar di dapatkan data yang valid untuk setiap pengambilan data dilakukan sebanyak 5 kali kemudian di ambil nilai rata-ratanya.

\section{HASIL DAN PEMBAHASAN}

Hasil

Hasil dari data penelitian pengambilan data daya torsi dan konsumsi bahan bakar menggunakan alat uji dynamometer (dynotes) memakai mesin motor 4 langkah dengan variasi poros engkol standrar dan poros engkol (crankshaft) CG200 yang menggunakan bahan bakar pertamax 92 .

Perhitungan peningkatan kapasitas mesin

1. Poros engkol standar

Spek mesin 4 langkah 160 CC:

Diameter piston (D) : $62 \mathrm{~mm}$

Panjang langkah (L) : : 49,5 mm

Rasio Kompresi $\quad: 9,0: 1$

Kapasitas mesin (Vs) $\quad=0,785 . D^{2} . \mathrm{L}$

$=0,785 .(63,5)^{2} \cdot 49,5$

$=3165,31 \times 49,5$

$=156,68 \mathrm{cc}$

Rasio Kompresi

$$
\begin{aligned}
& =\frac{\mathrm{Vs}+\mathrm{Vc}}{\mathrm{Vc}} \\
\frac{9,0}{1} & =\frac{156,68+\mathrm{Vc}}{\mathrm{Vc}} \\
9,0 \mathrm{Vc} & =156,68+\mathrm{Vc} \\
\mathrm{c}-1 \mathrm{Vc} & =156,68 \\
\mathrm{Vc} & =\frac{\mathbf{1 5 6 , 6 8}}{\mathbf{8 , 0}} \\
\mathrm{Vc} & =\mathbf{1 9 , 5 8} \mathrm{cc}
\end{aligned}
$$$$
9,0 \mathrm{Vc}-1 \mathrm{Vc}=156,68
$$

Jadi volume kompresinya (Vc) sebesar $\mathbf{1 9 , 5 8}$ cc

2. Poros engkol (crankshaft) CG200

Spek mesin setelah menggunakan cranksaft CG200:

Diameter piston (D) : $65 \mathrm{~mm}$

Panjang langkah (L) : : 62,2 mm

Volume kompresi $(\mathrm{Vc}) \quad: 19,58 \mathrm{cc}$

Kapasitas mesin (Vs) $\quad=0,785 . \mathrm{D}^{2} . \mathrm{L}$

$=0,785 .(65)^{2} \cdot 62,2$

$=3316,6 \times 62,2$

$=206,29 \mathrm{cc}$ 
Rasio Kompresi

$$
\begin{aligned}
& =\frac{V s+V c}{V c} \\
& =\frac{206,29+19,58}{19,58} \\
& =\mathbf{1 1 , 5}
\end{aligned}
$$

Jadi Rasio kompresinya menjadi 11,5 : 1

\section{Daya}

Contoh perhitungan daya pada pengambilan satu sempel pengujian :

$\mathrm{N}_{\mathrm{e}}=\mathrm{T} \times \omega$

$\omega=5000 \mathrm{rpm}=5000 \times 2 \times \pi \mathrm{rad} / 60 \mathrm{~s}$

$$
=5000 \times 2 \times 3,14 \mathrm{rad} / 60 \mathrm{~s}
$$$$
=523,3 \mathrm{rad} / \mathrm{s}
$$

A. Perhitungan daya poros engkol standar

$\mathrm{N}_{\mathrm{e}}=\mathrm{T} \times \omega=13.93 \mathrm{Nm} \times 523,3 \mathrm{rad} / \mathrm{s}$

$$
\begin{aligned}
& =7289.569 \mathrm{Watt} \\
& =\mathbf{7 , 2} \mathrm{KW} \\
& =\mathbf{9 6 , 5 5 3 6} \mathrm{HP} \text { pada } 5000 \mathrm{Rpm}
\end{aligned}
$$

B. Perhitungan daya poros engkol (crankshaft) CG200

$$
\begin{aligned}
\mathrm{N}_{\mathrm{e}}=\mathrm{T} \times \omega & =19,36 \mathrm{Nm} \times 523,3 \mathrm{rad} / \mathrm{s} \\
& =10131.088 \mathrm{Watt} \\
& =\mathbf{1 0 . 1} \mathbf{K W} \\
& =\mathbf{1 3 5 . 4 4 3 2} \mathbf{~ H P} \text { pada } 5000 \mathbf{R p m}
\end{aligned}
$$

Tabel 5. Daya yang Dihasilkan pada Poros Engkol (Crankshaft) Standar dan Poros Engkol (Crankshaft) CG200.

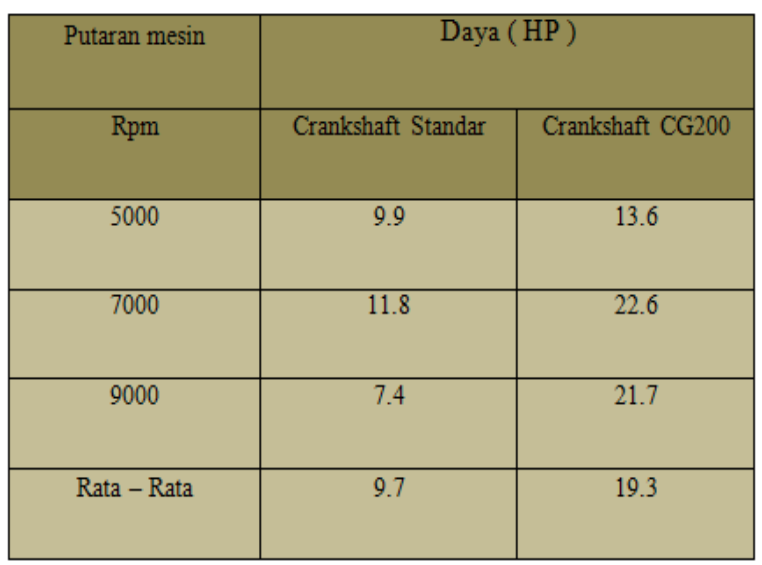

Tabel di atas menunjukan perbedaan daya terjadi pada semua rentan putaran mesin. Analisisnya :

a. Rata-rata perbedaan daya

$$
19,3-9,7=19,3 \mathrm{KW}
$$

$$
\frac{9,6}{19,3} \times 100 \%=49.7 \%
$$

b. Perbedaan daya pada putaran $5000 \mathrm{Rpm}$

$$
13,6-9,9=13,6 K W
$$$$
\frac{3,7}{13,6} x 100 \%=27,2 \%
$$

c. Perbedaan daya pada putaran $7000 \mathrm{Rpm}$

$22,6-11.8=10,8 \mathrm{KW}$

$$
\frac{10,8}{22,6} x 100 \%=47,3 \%
$$

d. Perbedaan daya pada putaran $9000 \mathrm{Rpm}$

$$
\begin{aligned}
& 21,7-7.4=14,3 \mathrm{KW} \\
& \frac{14,3}{21,7} x 100 \%=65,8 \%
\end{aligned}
$$

Perbandingan Daya (Rpm)

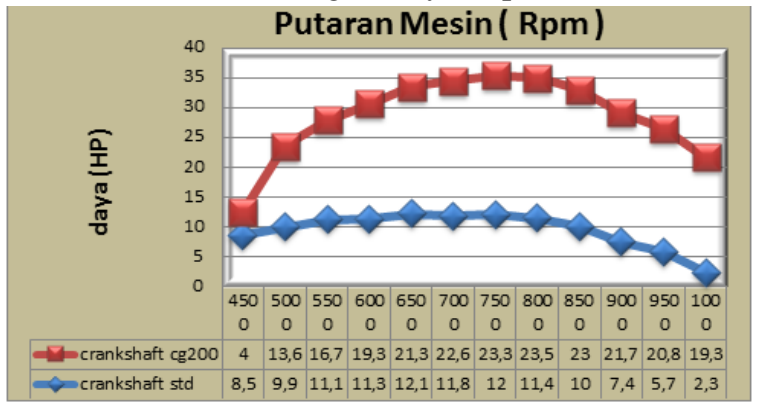

Gambar 3. Grafik Perbandingan Daya (Hp)

Menggunakan Poros Engkol (Crankshaft) dan Poros Engkol (Crankshaft) CG200

Rata-rata daya yang dihasilkan pada poros engkol modifikasi lebih besar 49,7\% yaitu sebanyak 9,6KW. Pada putaran mesin $5000 \mathrm{Rpm}$ perbedaan daya sebesar $27,2 \%$ yaitu sebesar $3,7 \mathrm{KW}$, pada putaran 7000 Rpm perbedaan daya sebesar 47,3\% yaitu $10,8 \mathrm{KW}$, sedangkan pada putaran mesin $9000 \mathrm{Rpm}$ perbedaan daya diketahui sebesar $65,8 \%$ yaitu sebesar $14,3 \mathrm{KW}$.

\section{Torsi}

Contoh perhitungan torsi :

A. Perhitungan torsi poros engkol standar

$$
\begin{aligned}
T & =(5252 \times P): N \\
& =(5252 \times 9,9): 5000 \\
& =51994,8: 5000 \\
& =\mathbf{1 0}, \mathbf{3} \mathbf{~ m}
\end{aligned}
$$

B. Perhitungan torsi poros engkol (crankshaft) CG200

$$
\begin{aligned}
T & =(5252 \times P): N \\
& =(5252 \times 13,6): 5000 \\
& =71427,2: 5000 \\
& =\mathbf{1 4}, \mathbf{2} \mathbf{~ m}
\end{aligned}
$$


Tabel 6. Torsi yang Dihasilkan pada Poros Engkol (Crankshaft) dan Poros Engkol (Crankshaft) CG200.

\begin{tabular}{|c|c|c|}
\hline Putaran mesin & \multicolumn{2}{|c|}{ Torsi (Nm) } \\
\hline Rpm & Crankshaft Standar & Crankshaft CG200 \\
\hline 5000 & 13.93 & 19.36 \\
\hline 7000 & 11.86 & 22.69 \\
\hline 9000 & 5.78 & 16.9 \\
\hline Rata - Rata & 10.5 & 19.65 \\
\hline
\end{tabular}

Tabel di atas menunjukan perbedaan torsi di seluruh rentan putaran mesin. Analisisnya :

a. Rata-rata perbedaan torsi

$19,65-10,5=9,15 \mathrm{Nm}$

$$
\frac{9,15}{19,65} \times 100 \%=\mathbf{4 6 , 5} \%
$$

b. Perbedaan torsi pada putaran $5000 \mathrm{Rpm}$

$19,36-13,93=\mathbf{5 , 4 3} \mathbf{~ N m}$

$$
\frac{5,34}{19,36} \times 100 \%=\mathbf{2 8 , 0} \%
$$

c. Perbedaan torsi pada putaran $7000 \mathrm{Rpm}$

$22,69-11,86=10,83 \mathrm{Nm}$

$$
\frac{10,83}{22,69} \times 100 \%=47,7 \%
$$

d. Perbedaan torsi pada putaran $9000 \mathrm{Rpm}$

$$
\begin{aligned}
& 16,90-5,78=11.12 \mathrm{Nm} \\
& \frac{11,12}{16,90} \times 100 \%=\mathbf{6 5 , 7} \%
\end{aligned}
$$

Perbandingan torsi (Nm)

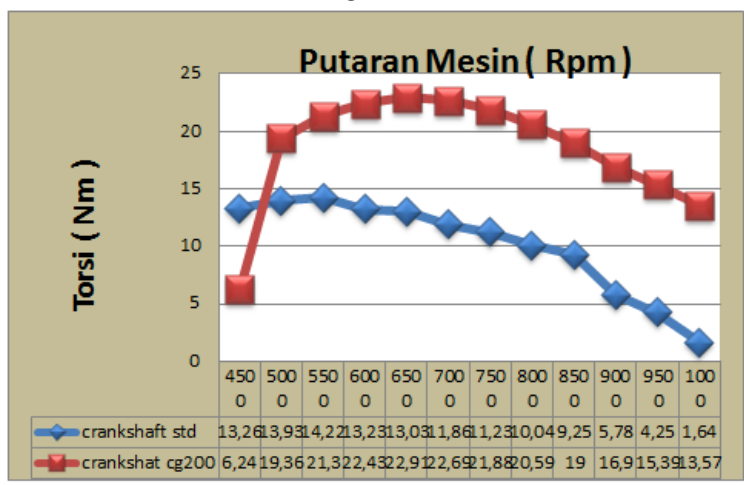

Gambar 4. Grafik Perbandingan Torsi (Nm)

Menggunakan Poros Engkol (Crankshaft) Standard dan Poros Engkol (Crankshaft) CG200

Rata-rata torsi yang dihasilkan pada poros engkol modifikasi lebih besar $46,5 \%$ yaitu sebanyak $9,15 \mathrm{Nm}$ jika dibandingkan dengan rata-rata torsi pada poros engkol standar. Pada putaran mesin 5000 Rpm perbedaan torsi sebesar 28,0\% yaitu sebesar 5,43 Nm. Pada putaran mesin 7000 Rpm perbedaan torsi sebesar 47,7\% yaitu sebesar 10,83 Nm, sedangkan pada putaran mesin $9000 \mathrm{Rpm}$ perbedaan torsi sebesar $65,7 \%$ yaitu sebesar $11,12 \mathrm{Nm}$.

\section{Konsumsi bahan bakar}

Perhitungan dan pembahasan dimulai dari proses pengambilan dan pengumpulan data meliputi daya, torsi dan konsumsi bahan bakar. Data yang dikumpulkan meliputi data spesifikasi objek penelitian dan hasil pengujian. Data tersebut diolah dengan perhitungan untuk mendapatkan variable yang diinginkan kemudian dilakukan pembahasan. Berikut ini merupakan proses pengumpulan data, perhitungan, dan pembahasan.

A. Perhitungan konsumsi bahan bakar

Dimana :

$\mathrm{b}=$ volume gelas ukur $(\mathrm{ml})$

$\mathrm{t} \quad=$ waktu $(\mathrm{s})$

$\rho b b=$ berat jenis bahan bakar $(\mathrm{kg} / \mathrm{l})$

$m f \quad=$ adalah penggunaan bahan bakar per jam pada

kondisi tertentu.

B. Konversi kilogram (kg) ke liter (L)

Berdasarkan rumus massa jenis di atas maka untuk mengkonversi berat ke volume adalah sebagai berikut.

Dimana :

$$
\begin{aligned}
& \mathrm{V}=\operatorname{volume}(\mathrm{L}) \\
& \mathrm{m}=\operatorname{massa}(\mathrm{Kg}) \\
& \mathrm{p}=\text { massa jenis } \\
& \qquad V=\frac{m}{p}
\end{aligned}
$$

Tabel 7. Berat Jenis Bahan Bakar Premium, Pertalite, dan Pertamax

\begin{tabular}{|c|c|c|}
\hline \multicolumn{3}{|c|}{ Berat Jenis Bahan Bakar } \\
\hline Premium & Pertalite & Pertamax \\
\hline 0.7471 & 0.715 & 0.723 \\
\hline
\end{tabular}

(Sumber : ww.otosip.com/2016)

$$
m f=\frac{b}{t} \times \frac{3600}{1000} \times \mathrm{Pbb}(\mathrm{kg} / \mathrm{jam})
$$

(Muku dan Sukadana, 2009: 29)

C. Perhitungan konsumsi bahan bakar menggunakan poros engkol (crankshaft) CG200

$$
m f=\frac{500 m l}{25 m e n i t} x \frac{3600}{1000} \times 0,723
$$




$$
\begin{aligned}
& =\frac{500}{1500} \times \frac{3600}{1000} \times 0,723 \\
& =0,8676(\mathrm{~kg} / \mathbf{j a m}) \\
\boldsymbol{V} & =\frac{\mathbf{0 , 8 6 7 6}}{\mathbf{0 , 7 2 3}} \\
& =\mathbf{1}, 2 \text { liter } / \mathbf{j a m}
\end{aligned}
$$

D. Perhitungan konsumsi bahan bakar menggunakan standar

$$
\begin{aligned}
m f & =\frac{500 \mathrm{ml}}{20 \text { menit }} \times \frac{3600}{1000} \times 0,723 \\
& =\frac{500}{1200} \times \frac{3600}{1000} \times 0,723 \\
& =\mathbf{1}, \mathbf{0 8 4 5 0}(\mathrm{kg} / \mathbf{j a m}) \\
\boldsymbol{V} & =\frac{\mathbf{1 , 0 8 4 5 0}}{\mathbf{0 , 7 2 3}} \\
& =\mathbf{1}, \mathbf{5} \text { liter } / \text { jam }
\end{aligned}
$$

\section{Pembahasan}

Daya

Berdasarkan penelitian yang telah dilakukan diperoleh data perbedaan daya yang dihasilkan pada masing-masing poros engkol. Pada grafik 4.1 di atas menunjukan rata-rata daya lebih besar didapatkan pada poros engkol modifikasi.

Perbedaan daya yang dihasilkan karena adanya perubahan pada panjang langkah yang dilakukan pada poros engkol dengan menggeser posisi big end batang torak menjadi lebih tinggi. Hal ini akan membuat rasio kompresi menjadi lebih tinggi. Bila rasio kompresi dipertinggi, tekanan pembakaran akan bertambah dan dari mesin akan diperoleh output yang besar (Muku dan Sukadana, 2009:28).

Selain rasio kompresi yang tinggi, nilai oktan bahan bakar juga hal yang mempengaruhi perbedaan daya yang dihasilkan, agar motor tetap menghasilkan tenaga yang besar tetapi tidak menimbulkan detonasi maka sebaiknya menggunakan bahan bakar yang nilai oktannya tinggi sehingga tahan terhadap tekanan kompresi yang tinggi (Suyanto, 1989:265).

Setelah dilakukan beberapa kali pengujian, menghasilkan daya tertinggi yaitu sebesar 47,3\% yaitu $10,8 \mathrm{KW}$ pada poros engkol modifikasi, sedangkan daya terkecil didapat pada poros engkol standar yang memakai bahan bakar pertamax yaitu hanya sebesar 7,2KW pada putaran 5000 Rpm, Dapat disimpulkan dari hasil penelitian yang telah dilakukan pada sepeda motor 4 Langkah 160 CC bahwa daya yang dihasilkan pada poros engkol modifikasi lebih besar dibanding dengan poros engkol standar dengan penggunaan bahan bakar pertamax.
Torsi

Berdasarkan penelitian yang telah dilakukan diperoleh data perbedaan torsi yang dihasilkan pada masing-masing poros engkol dan penggunaan jenis bahan bakar. Pada grafik 4.2 di atas menunjukan ratarata torsi lebih besar didapatkan pada poros engkol modifikasi dibandingkan dengan poros engkol standar yang menggunakan bahan bakar pertamax.

Perbedaan torsi yang dihasilkan karena adanya perbedaan rasio kompresi dan angka oktan dari bahan bakar yang digunakan. Rasio kompresi menjadi lebih tinggi karena adanya perubahan posisi big end batang torak pada poros engkol menjadi lebih tinggi. Oleh karena itulah maka motor yang lingkaran engkolnya besar tenaga yang dihasilkan akan lebih besar dibanding motor yang berdiameter atau radius engkol kecil, yang berarti pula motor dengan langkah yang panjang akan menghasilkan momen yang lebih besar (Suyanto, 1989:35).

\section{Konsumsi bahan bakar}

Berdasarkan penelitian yang telah dilakukan diperoleh data perbedaan konsumsi bahan bakar yang dihasilkan pada masing-masing poros engkol. Pada grafik 4.3 di atas menunjukan rata-rata konsumsi bahan bakar lebih rendah didapatkan pada poros engkol modifikasi yang menggunakan bahan bakar pertamax.

Adanya pebedaan konsumsi bahan bakar dikarenakan adanya perbedaan rasio kompresi dan perbedaan angka oktan bahan bakar. Rasio kompresi yang tinggi akan menghasilkan tekanan kompresi yang tinggi, sehingga diperlukan bahan bakar dengan angka oktan yang tinggi agar hasil pembakarannya sempurna. Sehingga selain rasio kompresi yang tinggi, nilai oktan bahan bakar juga hal yang mempengaruhi perbedaan konsumsi bahan bakar (Muku dan Sukadana, 2009:30). Pemakaian bahan bakar bensin yang ber angka oktan tinggi akan menghasilkan konsumsi bahan bakar yang lebih rendah/irit. Konsumsi bahan bakar rendah karena proses pembakaran yang sempurna dan tidak terjadi detonasi (Rajagukguk, 2012:10).

Setelah dilakukan beberapa kali pengujian, konsumsi bahan bakar terendah diperoleh pada motor yang menggunakan poros engkol (crankshaft) CG200 yaitu sebesar 1,2 liter/jam, sedangkan konsumsi bahan bakar terbesar didapat pada penggunaan poros engkol standar yaitu sebesar 1,5 liter/jam.

Dapat disimpulkan bahawa penelitian yang telah dilakukan pada sepeda motor 4 Langkah 160 CC 
bahwa konsumsi bahan bakar yang dihasilkan pada poros engkol (crankshaft) CG200 mempunyai rasio kompresi yang tinggi dan penggunaan bahan bakar yang sesuai rasio kompresi mesin, hal ini menunjukan bahawa pembakaran di ruang bakar lebih sempurna dan memaksimalkan konsumsi bahan bakan.

\section{PENUTUP}

\section{Kesimpulan}

Berdasarkan hasil penelitian yang telah dilakukan, maka dapat disimpulkan sebagai berikut:

1. Perbedaan daya dan torsi yang dihasilkan lebih maksimal karena perbedaan panjang langkah dari poros engkol (crankshaft) standard yaitu 49,5mm dan pada poros engkol (crankshaft) CG200 $62,2 \mathrm{~mm}$ yang membuat rasio kompresi semakin tinggi.

2. Perbedaan daya sekitar 49,7 \%, dihasilkan oleh poros engkol (Crankshaft) standard yang di ambil rata - rata sekitar 9,7 HP dan pada poros engkol (Crankshaft) CG200 yaitu 19,3 HP.

3. Perbedaan torsi sekitar 46,5\%, dihasilkan oleh poros engkol (Crankshaft) standard yang di ambil rata - rata sekitar 10,5 $\mathrm{Nm}$ dan pada poros engkol (Crankshaft) CG200 yaitu 19,65 Nm.

4. Konsumsi bahan bakar terendah diperoleh pada motor yang menggunakan poros engkol (crankshaft) CG200 yaitu sebesar 1,2 liter/jam, sedangkan konsumsi bahan bakar terbesar didapat pada penggunaan poros engkol (crankshaft) standar yaitu sebesar 1,5 liter/jam.

\section{Saran}

1. Penggunaan poros engkol (crankshaft) CG200 dapat meningkatkan daya dan torsi secara signifikan. Hal ini dapat dimanfaatkan pada sepeda motor yang digunakan dalam olahraga otomotif seperti balap motor.

2. Perlu dilakukan penelitian lebih lanjut mengenai pengaruh stroke up pada sepeda motor terhadap performa dan emisi gas buang yang menggunakan bahan bakar pertalite, pertamax dan pertamax plus.

3. Perlu di tambah variasi stroke up poros engkol yang diteliti, misalnya stroke up sebesar $6 \mathrm{~mm}, 7$ $\mathrm{mm}$ dan $8 \mathrm{~mm}$.

4. Perlu diteliti lebih lanjut tentang perubahan geometri mesin akibat poros engkol yang dimodifikasi dengan cara stroke up.

\section{DAFTAR PUSTAKA}

Dahayu, (2016). Onine https://ratmotorsport.co/2009/ 02/18/rasio-kompresi-dan-tenaga/ . (Diakses pada tanggal 24 mei 2017).

Irawan Andik, (2015). "Karakteristik Motor Bensin 4Langkah dengan Variasi Folume Silinder dan Perbandingan Kompresi”. jurnal Jurnal Ilmiah INOVASI, Vol. 15 No. 1 Hal. 47 - 51, Januari - April 2015, ISSN 1411 -5549

Fauzi, (2015).

Online

https://eduengineering.wordpress com/2015/01/10/prinsip-kerja-motor-bakardan komponennya/ . (Diakses pada tanggal 24 mei 2017)

M.Nugroho huda khoirul, (2016) . "Pengaruh Stroke Up terhadap Performa Mesin pada Sepeda Motor 4 Langkah yang Menggunakan Bahan Bakar Pertamax, Pertamax Plus dan Bensol". Skripsi. Semarang: FT Universitas Negeri Semarang.

Mufarida, Nely Ana (2016). “Analisis Prestasi Kerja Motor 4 Tak Dengan Penggunaan Turbo Cyclone". Jurnal Kajian Ilmiah dan Teknologi Teknik Mesin. Volume 01, Nomor 01, Agustus 2016 ISSN: 2528-6382.

Wjayanti Fitria dan Irwan Dadan, (2014). “Analisis Pengaruh Bentuk Permukaan Piston Terhadap Motor Mesin". Jurnal Imiah Teknik Mesin, Vol. 2, No. 1, Februari 2016 , Universitas Islam 45, Bekasi. 